\title{
Competencias Estaduais e Municipais Sobre Fornecimento de Saúde Pública e Medicamentos
}

\section{City and State competences about Supplying of Public Health and Medicines}

\author{
Artigo \\ Original \\ Original \\ Paper
}

Benevenuto Silva dos Santos 1

Palavras-chaves: Resumo

Federalismo O presente trabalho baseia-se em questões práticas em que tive oportunidade de atuar na defesa da Administração Pública Municipal, verificando a

Saúde Pública

Descentralização necessidade de diferenciar as competências traçadas pela Constituição Federal em matéria de saúde pública. A saúde pública gratuita é uma conquista do cidadão, principalmente daquele que necessita desse benefício por questões econômicas. O Sistema é pautado na descentralização, ocorrendo, no Estado do Rio de Janeiro, uma gestão pautada na ação municipal para ser bem claro. Entretanto, num modelo federativo, em que o postulado de repartição de competências se coaduna com o princípio da supremacia do interesse, preocupa-nos o fato de prefeitos assumirem e entenderem que a construção de um arcabouço hospitalar seja atribuição de sua esfera governamental, provocando uma gestão anti-econômica e ineficiente.

\begin{abstract}
This text considers some municipal public administration cases, all relating to public health. The main concern is to understand public (Federal) policies which affect municipal action in the health sector. Recent Federal policies for the health sector were established in Brazil by the 1988 Constitution. Free access to health services is important to most Brazilian citizens, particularly to those economically less privileged. In Brazil, matters relating to health are decentralized; in the case of the state of Rio de Janeiro, for example, management is municipal. In a Federal system, however, problems may arise when mayors and municipal authorities consider building hospitals: and so creating non-economic activities and producing inefficiencies for the health sector (i.e. negative effects resulting from unnecessary spending, bad financial management and budget administration mismanagement).
\end{abstract}

Key words:

Federalism

Públic Health

Decentralization

\section{Planejamento Governamental e Saúde Pública}

A promessa de construção de hospitais e de fornecimento de medicamento em tempo melhor tem sido uma constante no debate das eleições municipais. Várias críticas pairam sobre a gestão da saúde pública, envolvendo filas enormes e conseqüente demora no atendimento, omissão do Poder público em socorrer vítimas ou pacientes que requerem tratamento urgente, fornecimento de medicamento, etc.

A primeira solução é a promessa de mais postos de saúde, mais hospitais ou prontos-socorros (e ampliação do tempo de funcionamento das unidades de atendimento ao cidadão). A preocupação por parte da população com a situação do setor de saúde é lógica e compreensível; mas, ao mesmo tempo, 
digna de um raciocínio ignorante, em que o problema se encontra na gestão econômica e na avaliação dos resultados. A construção de um hospital pelo município, ou mesmo pelo Estado, com a esperança de adquirir mais recursos orçamentários da União, esbarra na necessidade de se pensar a efetiva necessidade de construção de um hospital. Mesmo porque vários hospitais, localizados numa mesma territorialidade, não significa atendimento melhor e imediato. Por outro lado, pode significar um enorme aumento de gastos públicos. Pergunta-se: se o Sistema Único de Saúde deve atender a normas gerais federais, por que não seria melhor, em municípios de pequeno porte, empreender a expansão de hospital já existente, ao invés de uma nova estrutura hospitalar.

A resposta imediata seria que tal planejamento causaria uma limitação ou intimidação na competência municipal de autogestão, base do nosso federalismo. Aqui, uma nova observação: em se tratando de Sistema Único de Saúde (SUS), é correto afirmar que o federalismo de plena separação de atribuições é aplicado?

Políticas públicas devem ser planejadas, principalmente se as despesas que lhe são decorrentes são anti-econômicas (ou comprometem a eficiência da administração pública).

O planejamento governamental é duplamente imperativo ${ }^{1}$, baseado na prévia programação financeira da administração pública e no planejamento de políticas públicas, agindo de acordo com a supremacia do interesse nacional sobre o local. Esta dimensão é importante para melhor aproveitamento das condicionantes territoriais, em consonância com os anseios da sociedade civil. Assim, a localização de um hospital, sua construção e todo gasto conseqüente dessa medida, seria analisado sob essa ótica, evitando o desperdício de dinheiro público². O pensamento popular de que quanto mais leitos, unidades, melhor para a população, esbarra na falta de premissa de que tal medida tenha como conseqüência a qualidade do serviço que será prestado ${ }^{3}$.

Talvez por esse fato, o Ministério da Saúde não efetue o credenciamento de qualquer hospital, para efeito de recebimento de verbas. Caberia, da mesma forma, aos Tribunais de Contas dos Estados ${ }^{4}$ analisar os fatores que fazem valer tais empreitadas por parte das Administrações Municipais, quais sejam, opção política pautada no relevante interesse público, inveja administrativa pela localidade não possuir hospital, falta de suporte hospitalar por parte do Estado ou a simples cobrança ou pressão da sociedade.

\section{A Cooperação e Ação Integrada dos Entes Federativos - Uma Leitura do Artigo 23 da Constituição da Federação}

Não se pode diferenciar a responsabilidade do ente municipal sem atingir as demais esferas políticas, considerando que a própria Carta Maior indica a ação de todas as esferas.

Art. 23. É competência comum da União, dos Estados, do Distrito Federal e dos Municípios:

$[\ldots]$

II - cuidar da saúde e assistência social, da proteção e garantia das pessoas portadoras de deficiência; $[\ldots]$

Para SLAIBI (2004, p. 814) a Constituição não esgotou o rol de competências comuns em seu art. 23, podendo citar outros casos de competências afetas às três esferas governamentais, como, por exemplo, art. 144, art. 205 e art. 227. Complementando a explanação do doutrinador, podemos inserir os dispositivos referentes à saúde pública neste mesmo contexto, cujo papel regulatório cabe à União, na qualidade de gestora nacional do SUS.

\footnotetext{
$1 \mathrm{O}$ art. 174, Constituição Federal, faz esse previsão de forma expressa, como uma forma do Estado promover o desenvolvimento.

${ }^{2}$ Um dos maiores problemas nos países mais pobres é que os limitados recursos públicos são aplicados, muitas vezes, de forma pouco criteriosa e sem os controles devidos - uma situação bem diferente do que ocorre nos países avançados, onde, além disso, os fundos públicos são bem mais abundantes. Sistemas políticos e de administração pública, perdulários e ineficientes, são, sem dúvida, os piores inimigos de uma sociedade marcada pelo subdesenvolvimento (FONSECA 2006, p. 10).

${ }^{3} \mathrm{O}$ aumento de gastos públicos é objeto de estudo do direito financeiro, que classifica as despesas em correntes e de capital. As despesas de capital são aquelas que provocam um incremento do PIB, associadas às políticas de investimentos em equipamentos públicos e à infra-estrutura, enquanto as despesas correntes relacionam-se ao custeio da máquina estatal. Ou seja, o aumento do número de equipamentos e instalações públicas provoca, conseqüentemente, em aumento dos gastos correntes.

4 Dentre os tipos de auditoria temos administrativa, financeira, patrimonial e operacional, sendo admitida auditoria de conformidade, verificando a consecução de programas e a qualidade do gasto empreendido.
} 
MOREIRA NETO (2004, p. 500) descreve que o ordenamento social da saúde é exercido como uma exceção ao princípio federativo, qual seja de separação das atribuições e funções entre as esferas governamentais. Esse sistema, que é um subsistema da seguridade social, segue o princípio da solidariedade. COIMBRA (1998, p. 48), afirma que o princípio da solidariedade é a base constitucional para o custeio dos programas de seguridade social, de forma direta e indireta, mediante contribuições sociais e recursos provenientes da receita tributária da União. Isso significa que a atuação municipal segue exclusivamente a orientação federal. Esta apresenta as diretrizes gerais do Sistema. Assim o faz com o fornecimento de medicamentos, que segue uma lista básica de disponibilidade à população.

Sabe-se que as competências federativas decorrem da Constituição Federal. $\mathrm{O}$ máximo que a legislação ordinária e complementar podem fazer é descrever as diretrizes gerais e específicas de cada ente federativo. Assim, não identificamos a possibilidade de qualquer imposição à atuação do Município nas questões referentes à prestação de todos os serviços públicos afetos à saúde que ultrapasse estas diretrizes. Confortam-se as Esferas governamentais superiores em delegar a responsabilidade e o ônus de um sistema complexo e problemático ao Ente municipal.

A competência comum, descrita no art. 23 da Constituição, impõe atuação cooperada dos três entes federativos, baseado num modelo de redução de desigualdades regionais em favor de uma progressiva igualação das condições sociais de vida em todo território nacional, salienta BERCOVICI (2004, p. 57). O autor conclui que a materialização da coordenação encontra-se nas competências concorrentes ${ }^{5}$, estabelecidas no art. 24, Constituição Federal.

Cabe-nos aqui ressaltar que a competência concorrente vincula União, Estados e o Distrito Federal em matérias de abrangência nacional e regional, cabendo à união legislar sobre questões de caráter geral e aos Estados nos aspectos peculiares de sua territorialidade. A realidade e a ponderação atuarão na distribuição das competências.
Por princípio de federalismo, a entidade que assume determinada função tem o direito de receber os instrumentos necessários à realização destes objetivos. O orçamento público é o espelho desta realidade vivida pelo Poder Público.

MEIRELLES (2006, p. 461), em obra destinada ao estudo do direito administrativo municipal, reproduz que, tratando-se de competência concorrente e supletiva, sempre que a esfera mais alta passar a prover o mesmo assunto de modo diverso do provimento inferior fica afastada a regulamentação da entidade menor.

\section{Os Estados e os Municípios na Repartição de Atribuições na Esfera do Sistema Único de Saúde}

As Prefeituras Municipais, por intermédio de suas secretarias de saúde e de fundo municipais de saúde, compõem o Sistema Único de Saúde, SUS, formado também por órgãos estaduais (secretarias estaduais de saúde, hospitais estaduais, serviços epidemiológicos, farmácia, vigilância sanitária, hemocentros) e federais (Ministério da Saúde, hospitais, Fundação Nacional de Saúde, dentre outros).

A Constituição Federal não reproduz com exatidão as áreas de atuação desses serviços prestados pelo Poder Público de cada esfera política, que não são de competência expressa, mas de atuação comum e integrada, nos seguintes termos:

Art. 198. As ações e serviços públicos de saúde integram uma rede regionalizada e hierarquizada e constitui um sistema único, organizado de acordo com as seguintes diretrizes:

I - descentralização, com direção única em cada esfera de governo;

II - atendimento integral, com prioridade para as atividades preventivas, sem prejuízo dos serviços assistenciais;

\section{$[\ldots]$}

Art. 200. Ao sistema único de saúde compete, além de outras atribuições, nos termos da lei:

I - controlar e fiscalizar procedimentos, produtos e substancias de interesse para a saúde e participar da produção de medicamento, equipamentos, imunobiológicos, hemoderivados e outros insumos; 
Do exposto trazido, nos termos do texto retirado da Lei 8.080/90, que regulamenta o funcionamento do SUS, ao Estado-membro e aos Municípios competem a Estados e Municípios:

Art. 17. À direção estadual do Sistema Único de Saúde (SUS) compete:

I - promover a descentralização para os Municípios dos serviços e das ações de saúde;

II - acompanhar, controlar e avaliar as redes hierarquizadas do Sistema Único de Saúde (SUS);

III - prestar apoio técnico e financeiro aos Municípios e executar supletivamente ações e serviços de saúde; $[\ldots]$

VIII - em caráter suplementar, formular, executar, acompanhar e avaliar a política de insumos e equipamentos para a saúde;

$[\ldots]$

Art. 18. À direção municipal do Sistema de Saúde (SUS) compete:

I - planejar, organizar, controlar e avaliar as ações e os serviços de saúde e gerir e executar os serviços públicos de saúde;

II - participar do planejamento, programação e organização da rede regionalizada e hierarquizada do Sistema Único de Saúde (SUS), em articulação com sua direção estadual;

III - participar da execução, controle e avaliação das ações referentes às condições e aos ambientes de trabalho;

$[\ldots]$

V - dar execução, no âmbito municipal, à política de insumos e equipamentos para a saúde;

Podemos catalogar as respectivas atuações administrativas dos Estados-membros nos seguintes setores:

- Fomentar, em caráter suplementar, executar, acompanhar e avaliar a política de insumos e equipamentos para a saúde, incluídos fornecimento de medicamentos que não estejam ofertados em caráter regular;

- Identificar estabelecimentos hospitalares de referência e gerir sistemas públicos de alta complexidade, de referência estadual e regional;

Nesse raciocínio lógico e sistemático das competências constitucionais, verificase que o Município atuaria após a entrada do Ente Estadual como executor de uma medida administrativa já definida em nível federativo maior, dando execução, no âmbito municipal, à política de insumos e equipamentos para a saúde. Podemos traduzir o termo que "dar execução" significaria implementar um sistema ou dar cumprimento a medidas administrativas já estabelecidas.

A atuação suplementar possui um referencial constitucional, nos termos do artigo 24, que trata da competência concorrente, conforme dito anteriormente. Nesse tipo de competência, os Estados legislam suplementarmente sobre determinadas matérias, em aspectos restritos à sua abrangência territorial, sendo as diretrizes gerais (ou nacionais) traçadas pela União. Também os Municípios assumem competências suplementares em matérias como meio ambiente, educação, saúde, dentre outros, naquilo que tange à prestação desses serviços no âmbito local ${ }^{6}$, conforme nos mostra o artigo 30, Constituição Federal. Assim, a atuação suplementar, decorre de diretrizes e aspectos gerais normativos traçados pelos entes federativos maiores. A Constituição nos deixa claro que as questões de interesse local são assumidas pelos Municípios, em razão da dita suplementariedade. Sendo regra a descentralização administrativa, devidamente financiada por recursos das demais esferas governamentais, o interesse local não é fator preponderante na transferência de atribuições na esfera do SUS, por tornar-se difícil diferenciar aquilo que é local daquilo não seja extra-local $^{7}$. Na realidade, temos vivenciado que aquilo que não for de alta complexidade será considerado de interesse local, haja vista o princípio da descentralização.

Para tanto, a própria Constituição da Federação brasileira determina a competência do Município para prestar atendimento à saúde, com a devida assistência técnica e financeira da União e dos Estados. É evidente que os princípios da razoabilidade, da realidade, de eficiência e da economicidade devem ser aplicados à finalidade da norma. $\mathrm{O}$ que for possível realizar de maneira mais econômica na esfera local, assim o será. Para MEIRELLES (2006, p. 465), a ação do Município no setor de saúde pública deve entrosar-se com a União e o Estado-membro, dado o alto custo dos procedimentos preventivos e curativos a empregar, reforçando que as medidas

${ }^{6}$ Vide SILVA (2004, p. 624).

7 Luís Roberto Barroso (2006, p. 161-88) sintetiza que a competência federal privativa é enumerada (no elenco do art. 22), a municipal é expressa, mas não enumerada (por isto que extraída da cláusula genérica "interesse local") e a estadual é remanescente ou residual. 
higiênicas e profiláticas, para terem eficácia, devem se estender a grandes áreas, que, na maioria das vezes, transcendem os limites territoriais dos Municípios.

Isso reforça a atuação do Município em questões de pequena dimensão na condução dos serviços de saúde e o tornam parceiros nos procedimento de maior amplitude. Assim, tudo que estiver além dos serviços regularmente prestados pelo Município, no contexto do SUS, incluindo medicamentos para tratamento especializado, deve ser assumido, num primeiro instante, pelos Estados-membros, para, posteriormente, ser assumido pelos Municípios, se o usuário fizer uso constante de tal medicamento. Ao Estado, cabe assumir sua atribuição de fomento e apresentar instrumentos efetivos de atuação, a fim de que o Município trabalhe como executor do Sistema em nível local.

\section{Do Perfil do Sistema Único de Saúde}

A maior parte dos recursos financeiros dos órgãos de saúde pública municipal provém do seu próprio orçamento. Tais valores são planejados em função das receitas tributárias a serem arrecadadas pela própria entidade federativa municipal e de transferências constitucionais e legais.

As diretrizes do SUS conferem muitas obrigações às unidades e hospitais municipais e aos demais serviços públicos de saúde prestados pela estrutura local de Poder. Ocorre que esta estrutura é bastante limitada. Apenas ilustrando, as faturas dos serviços prestados são mensais, mas o pagamento pelo SUS não é imediato.

O montante de verbas federais e estaduais destinadas à saúde não cobre todas as necessidades do Sistema. Em se tratando de um Município que detém a gestão de um hospital próprio, com recursos limitados, será justo exigir do Ente Federativo maior que presta suporte financeiro com despesas que vão além de sua estrutura.

Quanto aos produtos de uso imediato e essencial, cuja negativa por parte do Poder Público importe em dano vital ao interessado, os Municípios mantém farmácias prontas para tais atendimentos, seguindo orientação normativa e tabelar do SUS.

A interpretação sistemática apresentada pelos órgãos que defendem a tese de municipalização de atendimentos complexos pauta-se na prevalência do art. 18 da Lei 8.080/90. Traduz-se que a sistemática constitucional de oferta de medicamentos possui um caráter de impacto local, tendo por base a mencionada Lei 8.080/90. Lamentamos tal visão e discordamos frontalmente, pois os critériosdarazoabilidadeedaproporcionalidade alicerçam nosso pensamento, ainda que a política de medicamento e atendimento esteja padronizada por legislação federal. Se determinada lei federal apresentar impacto insuportável nas contas relativas à aquisição de determinado produto, as atribuições delegadas no âmbito do SUS, descritas no art.200, Constituição Federal, estarão comprometidas por motivo de ineficácia na gestão local.

\section{Da Capacidade Econômica dos Entes Federativos}

A capacidade de arrecadação do Poder Público Municipal, merece atenção por parte da Federação, uma vez que a gama de serviços prestados e de recursos constitucionais e legais que lhe são disponíveis o coloca em situação desconfortável.

TORRES (p. 297), doutrinador de assuntos financeiros, denomina nosso federalismo como pendular, que alterna épocas de centralização de recursos financeiros e poder nas mãos do Governo Federal com outras em que se privilegiam os entes menores, tudo a coincidir com as vicissitudes do autoritarismo político.

O federalismo fiscal provoca atuação compartilhada e integrada de todas as esferas políticas, sendo característica marcante desse modelo a autonomia administrativa e tributária. Todos os entes são responsáveis por prestação de políticas públicas que garantam à população todos os direitos constitucionais e legais que lhe são postos. Entendemos que a atuação comum de cada ente, sem descrição das competências de forma expressa, impõe a repartição eqüitativa do ônus, em completa simetria com a distribuição do bônus tributário e fiscal. 


\section{Da Política Nacional de Medicamentos}

A política de medicamentos de caráter excepcional é programa que visa garantir à população medicamentos de alto custo ou de uso contínuo. Estes medicamentos são de elevado valor unitário, tornando seu custo excessivo aos cofres municipais.

Os medicamentos excepcionais são classificados pelo Ministério da Saúde, por grupos e tabelas, por intermédio de portaria do Ministro da Saúde. Cabe ao gestor federal (leia-se Ministério da Saúde) co-financiar o programa através de destinação de recursos aos gestores locais (leia-se Estados e Municípios).

Nos termos da Norma Operacional da Assistência à Saúde (NOAS-SUS 01/01), em seu item 57, g, é de responsabilidade dos Estados-membros a gestão das atividades referentes a medicamentos excepcionais, cabendo-lhe a elaboração do Plano Estadual de Saúde, e do Plano Diretor de Regionalização, incluindo o Plano Diretor de Investimentos e Programação Pactuada e Integrada; a coordenação da PPI do estado, contendo a referência intermunicipal e pactos de negociação na CIB para alocação dos recursos; a gestão das atividades referentes a tratamento fora de domicílio para referência interestadual, medicamentos excepcionais, central de transplantes; e a formulação e execução da política estadual de assistência farmacêutica, de acordo com a política nacional.

A regionalização ${ }^{8}$ do acesso à saúde constitui uma das bases do SUS, instituindo o plano diretor regional ${ }^{9}$ como instrumento de ordenamento do processo de regionalização da assistência em cada estado e no Distrito Federal, baseado nos objetivos de definição de prioridades de intervenção coerentes com as necessidades de saúde da população e garantia de acesso dos cidadãos a todos os níveis de atenção. Por orientação do Ministério da Saúde:

O PDR fundamenta-se na conformação de sistemas funcionais e resolutivos de assistência à saúde, por meio da organização dos territórios estaduais em regiões /micro-regiões e módulos assistenciais; da conformação de redes hierarquizadas de serviços; do estabelecimento de mecanismos e fluxos de referência e contra-referência intermunicipais, objetivando garantir a integralidade da assistência e o acesso da população aos serviços e ações de saúde de acordo com suas necessidades.

AUnião financia parte deste programa de medicamentos excepcionais, mediante transferência trimestral de recursos ao Fundo Estadual de Saúde, calculado com base nas informações fornecidas pelas secretarias estaduais de saúde, ao emitirem as respectivas APACs (autorizações de procedimentos em alta complexidade/custo), cabendo aos Estados o financiamento complementar ${ }^{10}$.

A Política Nacional de Medicamentos tem repercussão nacional, por força de suas possíveis conseqüências em outras áreas da produção e da economia. Não podemos nos esquecer de que a interpretação das competências constitucionais passa por uma teoria de poderes implícitos na própria Constituição. Para SCHWARTZ (1984, p. 14), embora o Governo Federal tenha competências enumeradas, ficou asseverado, no debate norteamericano sobre os poderes da União, que sua autoridade não está descrita nos mínimos detalhes na Constituição, sendo reconhecido os poderes necessários e apropriados para o efetivo exercício dos poderes expressos ${ }^{11}$; esta ficou conhecida como a doutrina dos poderes implícitos. Esta teoria aplica-se à União, em sentido inverso, combinando critérios de gestão, controle e execução, que, em

\footnotetext{
${ }^{8} \mathrm{O}$ conceito da região de saúde é apresentado no diploma normativo, da seguinte forma: Região de Saúde - base territorial de planejamento da atenção à saúde, não necessariamente coincidente com a divisão administrativa do estado, a ser definida pela Secretaria Estadual de Saúde, de acordo com as especificidades e estratégias de regionalização da saúde em cada estado, considerando as características demográficas, socioeconômicas, geográficas, sanitárias, epidemiológicas, oferta de serviços, relações entre municípios, entre outras. Dependendo do modelo de regionalização adotado, um estado pode se dividir em macro-regiões, regiões e/ou microrregiões de saúde. Por sua vez, a menor base territorial de planejamento regionalizado, seja uma região ou uma microrregião de saúde, pode compreender um ou mais módulos assistenciais.

9 Vale ressalta a visão regional do poder exercido pelos estados-membros na ótica de Paulo Bonavides, defensor da constitucionalização das regiões. A despeito da regionalização defendida pelo autor assumir aplicação distinta do que se pretende indicar neste trabalho, o conjunto de Municípios assume aspectos regionais, tal qual ocorre nas regiões metropolitanas. Vide BONAVIDES (2004, p. 359).

${ }^{10}$ www.saopaulo.sp.gov.br/secretariadasaude

${ }^{11}$ Podemos mencionar o caso da constitucionalidade da incorporação pelo Congresso Federal, em 1816, do Banco dos Estados Unidos, que funcionava como depositário de reservas governamentais e que estava autorizado a imprimir notas bancárias. A Constituição americana não definia expressamente este poder ao Congresso. SCHWARTZ, Bernard. O federalismo norteamericano atual: uma visão contemporânea. São Paulo: Forense Universitária, 1984, p. 14-15.
} 
conjunto com Estados, devem proporcionar meios para que o Sistema funcione, sendo a descentralização a conseqüência natural de plena eficiência. DI PIETRO (2006, p. 98) ressalta que o princípio da eficiência apresenta dois aspectos, quanto ao modo de atuação do agente, do qual se espera o desempenho possível, para lograr os melhores resultados, e quanto ao modo de organização e estruturação da Administração Pública.

Não havendo condições do Município atuar na gestão da saúde pública sem algum resíduo de competência legislativa, os procedimentos médicos e hospitalares fazem parte de um núcleo regulatório em que a União se torna gestora absoluta, pois esta atribuição faz parte de uma medida governamental federal, e não de caráter local. O reflexo da ausência de medicamentos, problema sentido pelas administrações públicas locais, decorre da ausência de outras políticas públicas, como saneamento básico, por exemplo, que sequer podem ser suportadas pelos municípios, em função de seu reduzido orçamento.

\section{Municipalização e Subsidiariedade}

O cidadão que necessita do atendimento do SUS localiza-se no Município. Mas, a necessidade de determinados medicamentos não é normal, sendo necessário um planejamento para aquisição em malotes, que analisados individualmente tornase ineficaz, se verificarmos princípio da economicidade contido no art. 70, Constituição Federal, se empreendida num contexto que abranja a realidade de cada esfera local.

O SUS é um instrumento de unificação da prestação dos serviços e não da distribuição de competências. Este sistema envolve aspectos federativos de cooperação entre as esferas governamentais, sem qualquer sombra de dúvidas. Então vejamos o que BARACHO (p. 31-2) delineia sobre este tema:

\footnotetext{
O princípio da subsidiariedade nem sempre se encontra inscrito em texto, nem os governantes reclamam que lê não possa ser levado em consideração. Trata-se de noção, na maioria das vezes, de ordem doutrinária. Não se pode esquecer, entretanto, que o princípio conduz a problemas essenciais da descentralização. As análises das reformas descentralizantes, em épocas anteriores, mostram que, freqüentemente, os debates verificam os aspectos de detalhe, perdendo a visão de conjunto. Muitas dessas investigações aparecem, hoje, como secundárias. Posteriormente,
}

na perspectiva do princípio da subsidiariedade, os problemas de descentralização são, essencialmente, questões de poderes e competência. Na elaboração de seu significado, natureza e demais aspectos, quanto à descentralização, entende-se que se deve ampliar a liberdade e os poderes das demais coletividades, por alguns denominados de territorialidade, sem sacrificar o que é essencial nas funções do Estado.

Dessa forma, conforme transcrevemos, a subsidiariedade sugerida merece ser interpretada à luz do nosso Federalismo. Significa descentralizar, sem desconectar com a essência da atividade descentraliza. Ou seja, quem delega a outra esfera ou entidade, não se ausenta. Ao contrário, deve estar presente. No Estado federal, o princípio da subsidiariedade deve contribuir para a criação de novas condições que ajudem e estimulem os vários tipos de interesses regionais e locais, respectivamente representados pelos Estados-membros e Municípios, coloca-nos ZIMMERMANN (2005, p. 204-5).

A descentralização estampada no art. 198 da Constituição não significa minimizar a atuação federal e estadual a questões de extremo e inadiável impacto regional e nacional, mas sim, na prevenção destes problemas, que decorrem da insuficiência de recursos públicos, cuja desigualdade tributária e econômica será suprida pelo ente federativo maior. A direção única não exclui a implantação de programas especiais de gestão pelas entidades (Federal e estaduais). No Município do Rio de Janeiro, por exemplo, há uma rede de hospitais e centros de medicinas especializadas de domínio da União, e mesmo hospitais universitários que, apesar da escassez dos recursos orçamentários, detêm uma tecnologia e um corpo de profissionais de alto nível, que não deveriam prestar auxílio a alguns postos e redes hospitalares locais.

O SUS é controlador e fiscalizador das políticas traçadas por colegiados e instâncias superiores, como o Conselho Nacional de Saúde e Ministério da Saúde.Adescentralização administrativa, para BASTOS (2005, p. 51), é instrumento de eficiência governamental, manifestando, neste mesmo diapasão, que a centralização retarda as decisões que sobrevêm a destempo, distanciando a vivência do problema da competência para decidi-lo, ou do poder para enfrentá-lo.

Utilizando o mesmo raciocínio do doutrinador, o exercício de determinada 
competência, ainda que em matéria comum a todos os entes federativos, somente será atingido em sua finalidade social se o ente federativo dispuser de meios de solucioná-lo.

\section{Conclusão}

O princípio da igualdade é condição primordial à sustentabilidade de nosso Estado de Direito; entendendo-o como uma norma de alto grau de otimização, adaptável às diversas situações que podem envolver interesses diversos.

No tema em questão, a prestação dos serviços de saúde pública, num Estado federal, deve ser pautada por políticas assistenciais integradas e articuladas pelos entes federativos maiores, dentro de uma escala de possibilidade de execução adequada ao contexto administrativo de cada territorialidade, planejado e integrado por conjunto de Municípios. Nesses casos de necessidades reais, o Estado não pode deixar de apresentar uma ação positiva. O papel principal das esferas governamentais nessa questão é garantir não somente a transferência de recursos, mas também a eficácia de políticas públicas governamentais. É possível que a entidade federativa atue na execução, em casos de maior complexidade, ao invés de forçar mais convênios e mais transferências legais de verbas do Tesouro.

Constitui um dos fundamentos da República Federativa do Brasil o combate às desigualdades e das justiças sociais e os diversos órgãos da administração pública devem atuar harmonicamente para este fim. Os problemas relacionados à saúde pública são conseqüências de históricas desigualdades regionais e locais, incluindo nisso a ausência do próprio Estado.

É imprescindível a regionalização efetiva dessas matérias, com participação executiva dos Estados, operando unidades hospitalares de referência e distribuindo medicamentos excepcionais, integrando Municípios, principalmente na região sul-fluminense, carente em demasia da presença do ente estadual.

\section{Referências}

BARACHO, José Alfredo, O Princípio da Subsidiariedade. Rio de Janeiro: Forense, 2000.
BARROSO, Luís Roberto, Temas de Direito Constitucional: Apontamentos sobre o princípio da legalidade. Tomo I, $2^{\mathrm{a}}$ ed. São Paulo: Renovar, 2006.

BASTOS, Celso Ribeiro, Curso de Direito Constitucional. São Paulo: Saraiva, 2005.

BERCOVICI, Gilberto. Dilemas do Estado Federal Brasileiro. Porto Alegre: Livraria do Advogado, 2004.

BONAVIDES, Paulo. Curso de Direito Constitucional. 14 ${ }^{\mathrm{a}}$ ed. São Paulo: Malheiros, 2004.

COIMBRA, J.R. Feijó. Direito Previdenciário. $9^{\mathrm{a}}$ ed. Rio de Janeiro: Edições Trabalhistas, 1998.

DI PIETRO, Maria Sylvia. Direito Administrativo. 19a ed. São Paulo: Atlas, 2006.

FONSECA, Manuel Alcino Ribeiro. Planejamento e Desenvolvimento Econômico. São Paulo: Thompson Learning, 2006.

MEIRELLES, Hely Lopes. Direito Administrativo Municipal. $15^{\mathrm{a}}$ ed. São Paulo: Malheiros, 2006.

MOREIRA NETO, Diogo de Figueiredo. Curso de direito administrativo. Forense: Rio de Janeiro, 2004.

SCHWARTZ, Bernard. O federalismo norteamericano atual: uma visão contemporânea. São Paulo: Forense Universitária, 1984.

SILVA, José Afonso. Curso de Direito Constitucional. $23^{\mathrm{a}}$ ed. São Paulo: Malheiros, 2004.

SLAIBI FILHO, Nagib. Direito Constitucional. Rio de Janeiro: Forense, 2004.

TORRES, Ricardo Lobo O Orçamento na Constituição. São Paulo: Renovar, 2000.

ZIMMERMANN, Augusto. Teoria geral do federalismo democrático. $2^{\mathrm{a}}$ ed. Rio de Janeiro: Lúmen Júris, 2005.

Endereço para Correspondência:

Prof. Benevenuto Silva dos Santos

Curso de Direito

benevenuto.santos@foa.org.br

Centro Universitário de Volta Redonda

Campus Três Poços

Av. Paulo Erlei Alves Abrantes, no 1325 ,

Três Poços - Volta Redonda / RJ

CEP: 27240-560 